flies (40 per cent). The DDT-resistant flies were observed to be similarly resistant to the bromine analogue $(\mathrm{I})$; but their resistance was not therefore associated with decreased absorption of the applied insecticide.

About $0.6 \mu 1$. of acetone containing $0.6 \mu \mathrm{gm}$. of (I*) was injected into each of groups of five susceptible and five resistant adult females. Injection was made dorsally into the thorax while the fly was under light cyclopropane anæsthesia. The injected dose was twice the L.D. 50 for DDT injected into a susceptible fly. Despite various precautions and despite the use of a precision micrometer-controlled syringe, the actual weights of $\left(I^{*}\right)$ injected, as determined radiometrically, varied considerably from fly to fly. The resistant flies of one group were killed by immersion in water at $90^{\circ} \mathrm{C}$. for 60 sec. before injection. Another group of resistant flies was disintegrated in a pestle and mortar before adding the insecticide. In another group the solution for injection contained the pyrethrin synergist piperonyl cyclonene at the rate of 1 por cent $(w / v)$ of solution. Finally, $50 \mathrm{ym}$. of $\left(\mathrm{I}^{*}\right)$ was applied topically to each of a group of resistant flies as in the penetration experiments.

After 0, 5 and $24 \mathrm{hr}$., groups of flies were macerated with anhydrous sodium sulphate and dilute sulphuric acid and the macerate extracted once at room temperature with a large excess of diethyl ether. About 95 per cent of the injected activity was recovered in the ethereal layers. The ether extract was then concentrated in a warm air stream, and aliquots roughly equivalent to one fly were examined by the radioactive tracer-chromatography technique described in an earlier communication ${ }^{5}$. Control runs indicated that under the experimental conditions (I*), (II*) or (III*) could be estimated to within about 5 per cent. Metabolism was observed only in the resistant flies. 23 per cent of the total weight of (I*) injected was recovered as the ethylene derivative (II*) after $5 \mathrm{hr}$. 57 per cent was recovered as (II*) after 24 hr. There was no evidence of the presence of the acetic acid derivative (III*) or of any metabolite of $R_{F}$ value sufficiently different from that of (I) or (II). In the experiment in which ( $\left.I^{*}\right)$ was applied topically, 8.7 per cent of the weight of (I*) absorbed was recovered as (II*) after $24 \mathrm{hr}$. No evidence of metabolism was found in the resistant flies which had been killed by heating or by disintegration before injection. The presence of piperonyl cyclonene appeared completely to inhibit the metabolic dehydrohalogenation (cf. Perry and Hoskins ${ }^{3}$ ).

These results suggest that the metabolism is enzymic in nature and that the enzyme system is either destroyed or becomes inaccessible on disintegration of the tissue. The metabolism appears to be insufficiently rapid to account for the successful resistance of the flies used in these experiments; alternatively, only a small fraction of the applied insecticide is involved at the site of action ; but it is this fraction which is metabolized (cf. Ferguson and Kearns ${ }^{1}$ ). It seemed possible that the mere presence of (TI) might account for the observed resistance, for example, by blocking the site of action. Experiments were made, therefore, in which mixtures of (I) and (II) were injected into, or applied to, susceptible flies. No evidence of resistance was observed.

It is planned to describe more fully this and work proceeding elsewhere. We wish to thank Dr. J. R. Busvine and Miss C. M. Harrison, of the London School of Hygiene and Tropical Medicine, for gifts of pupæ from their DDT-susceptible and DDTresistant strains of housefly, and for supplying data on the toxicity of normal DDT to these strains. This note is published by permission of the Department of Scientific and Industrial Research. [Sept. 28.

${ }^{1}$ Ferguson, W. C., and Kearns, C. W., J. Eicon. Entomol., 42, 810 (1949).

${ }^{2}$ Sternburg, J., Kearns, C. W., and Bruce, W. N., J. Econ. Entomol., 43, $214(1950)$.

s Perry, A. S., and Hoskins, W. M., Science, 111, 000 (1950).

4 Pratt, J. J., and Babers, F. H., Science, 112, 141 (1950).

-Winteringham, F. P. W., Harrison, A., and Bridges, R. G., Nature, $[166,999(1950)]$.

\section{MODERN TRENDS IN EDUCATION}

TN his Clayton'Memorial Lecture to the Manchester Literary and Philosophical Society, the Right Hon. R. A. Butler stated that the raising of the school. leaving age to fifteen has resulted in valuable worth. while courses in up-to-date secondary modern schools, but that limited success has been achieved in all-age unreorganized schools. The Education Act can never be properly interpreted until reorganization along the lines advocated by the Hadow Committee is complete, and in 1947 there were still 8,014 unreorganized schools; one-fifth of the young people in Britain of more than fourteen years of age are still not provided for in secondary modern schools. In the primary schools, too, it has been difficult to improve standards because of the size of classes. In 1947 there were still 3,425 pupils in primary classes of more than forty ; in these circumstances the teacher, Mr. Butler declared, is more a circus master than a prophet, and standards are bound to deteriorate.

Mr. Butler also showed that while the percentage of passes for the Higher School Certificate has remained constant at about 70 per cent over the past ten years, the number of students taking the examination in 1948 was more than twice the number taking the Higher School Certificate examination in 1938.

Of the general standards in schools, Mr. Butler suggested that in crowded schools pupils have not yet caught up the two-year backwardness which was the feature of the war period; in these schools pupils are still a year behind normal. In well-staffed schools with the best conditions, standards are up to the level of average times of peace. Newer methods of teaching have helped where teachers are competent to carry them out.

But the main danger which besets individual attainment of all-round excellence arises from undue specialization. It has always been a feature of the English tradition that the pupil is given a general background and that the faculties are developed in the broadest possible manner. Unfortunately to-day, when schools are apt to turn themselves into factories, no time is left for general study. Mr. Butler emphasized that he could not over-stress the wisdom of the words in the report on post-war education published in 1944 by a committee of the British Association which suggested that the sixth-form pupil, after devoting half his classwork and more of his private time to his speciality, should "pursue four general courses, covering respectively the humanities, the social sciences, the physical sciences, and the biological sciences, affording a connected and complete, if not profound, view of the whole of civilization. English expression, a modern language, and some- 
times mathematics might also be included in this programme."

Although agreeing with the decision that bright pupils may not take their School Certificates before they are sixteen, Mr. Butler believes that the education authorities will move, or may be led to move, towards the decision whereby people should take their real examination of quality when they are seventeen. Before that age there would have to be examinations, but they should be of the "test of attainment" type based partly upon internal record. Standards, however, cannot be maintained through the examination system. Standards can be restored only by re-establishing the one vital link in education, and that is the relationship between teacher and taught. This will be achieved by a restoration of liberty of interpretation to the schools of Britain and their masters.

T. H. HawkINS

\section{JUAN DE LA CIERVA FOUNDA- TION FOR TECHNICAL RESEARCH, SPAIN}

$\mathrm{A}^{\mathrm{N}}$ $\mathrm{N}$ illustrated brochure describing the origin, aims and organisation of the Juan de la Cierva Foundation for Technical Research* which under the Higher Council for Sciontific Research, created by the law of November 24, 1939, is responsible for all scientific work in Spain of a technical and industrial character, gives a fairly comprehensive picture of the organisation in Spain of scientific and industrial research. The Technical Advisory Council, which is the chief technical advisory organ of the governing body, is assisted by various technical committees which advise on the planning and development of any specific research activity.

Research work is carried out in a number of dependent institutes which investigate technical problems in a specific branch of applied science. These institutes include the Leonardo Torres Queredo Institute for Scientific Apparatus, the Institute for Technical Research on Building and Cement, the National Institute for Fuel Research, the Institute for Research on Fats, Oils and Related Products, the National Institute for Rationalization, the Welding Institute, the Iron and Steel Institute and the Institute of Electronics. The Foundation has also established a Department of Industrial Ferment. ation in the Institute of Microbiology, the Plastics Section of the Alonso Barba Chemical Institute, and the Section of Marine Biology in the Institute of Applied Biology, Barcelona. Research is also conducted by agreement with the Foundation in a number of independent institutions, such as the Institute for Technical Research, Barcelona, the Spanish Electro-Technical Association, the LaffonSelgas Laboratory for Electrical-Acoustical Research, the Institute for Experimental Research in Forestry the National Institute for Technical Aeronautics and the Cabro Sotelo Research Centre for Synthetic Fuels and Lubricating Oils.

Other institutions like the Alonso de Santa Cruz Institute of Physics, the Institute of Entomology, the Antonio de G. Rocasolano Institute of Physical Chemistry, the Daza de Valdés Optical Institute and

- Juan de la Cierva Foundation for Technical Research: its Organization and Development. Pp. 40. (Madrid : Juan de la Cierva the Institute for Soil Research, as well as the Universities of Madrid, Barcelona, Seville, Granada, Orviedo, and Valencia, are collaborating with the Foundation, while close liaison is fostered between the research centres of the Foundation and industry. The Foundation also seeks to encourage the training of research workers as well as the interchange of workers and of publications with foreign technical institutions. Brief notes on the work carried out by the institutes and research centres of the Foundation are included.

\section{THE UNIT OF HEAT}

TN 1948 the International Unions of Chemistry and of Physics, and the International Conference of Weights and Measures, agreed to adopt the joule as the unit of heat in place of the calorie ${ }^{1}$. A memorandum on this subject was recently prepared by Sir Charles Darwin, chairman of the Symbols Committee of the Royal Society. After careful consideration of this memorandum, the Council of the Royal Society recommended that, in future, in the Society's publications, all quantities of heat and related concepts such as specific heat, entropy, etc., should be expressed both in joules and in calories. To facilitate this, the Society has issued a pamphlet in which the text of Sir Charles's memorandum and the Council's recommendations, tables of conversion factors from various calories and British thermal units to joules, together with examples of their use in textual, tabular and diagrammatic matter, are printed. No indication is given, however, as to how these factors have been determined; but it is presumed that they are in accordance with the best available experimental data.

It is made clear in the memorandum that, in accordance with the statement of the First Law of Thermodynamics that heat is energy, the joule, of $10^{7}$ ergs, is the basic unit. This alone would not necessitate its use in actual practice; but it is well known that the several calories which are used are all different in value and that calorimetric work of high precision is invariably done electrically, involving electrical units which give results directly in joules to a high order of accuracy. Although the joule is theoretically the correct unit, it must be admitted that in the past nearly all work has been expressed in calories, and, doubtless, heat quantities expressed solely in joules may be unfamiliar to many men of science. For this reason, and in order to give prominence to the joule, it is recommended in the pamphlet that both the joule value and, in paren. theses, the equivalent value in calories be quoted. This is similar to the practice recently advocated of giving metric equivalents to British mechanical units when the latter are used. It is strange, however, to find that the textual example shown in the pamphlet uses the reverse order to that recommended, the heat of combustion of carbon monoxide in oxygen being given in k.cal. per mole and the equivalent joule value in parentheses.

The replacement of the calorie by the joule is intended only for strictly scientific work, and the hope is expressed that, by the publication by the Royal Society of this pamphlet, the practice advocated by the Council of the Royal Society will be recommended and followed by other scientific bodies.

1 Nature, 163, 427 and 164, 262 (1949). 